\title{
Solution Properties of Combretum Glutinosum (Habeil) Gum
}

\author{
M. H. Awad \\ Correspondence: M. H. Awad, Department of Chemistry, Faculty of Arts and Sciences - Kasr Khiar, Al-Mergheb \\ University- Libya. Email: muhash.co1@gmail.com
}

Received: May 30, 2015 Accepted: July 1, 2015 Online Published: August 14, 2015

doi:10.5539/ijc.v7n2p49 URL: http://dx.doi.org/10.5539/ijc.v7n2p49

\begin{abstract}
The solubility of Combretum glutinosum gum in distilled water ranged from 30 to $40 \%$ and gel fraction ranges between 60 to $70 \%$. It was found that the gum solubility increased with increase the $\mathrm{pH}$ of solution. The reduced viscosity of Gum Habeil in distilled water was increased with decrease the concentration of gum solution, and this is the a behavior of ionic polysaccharide solutions, for that Huggins and Kraemer equations are incapable to derive the intrinsic viscosity value of aqueous gum solution. Some extrapolated equations such as Fouss, Schulz -Blaschke, Martin, Heller, and Fedors equations used to estimate the optimum model for measurement intrinsic viscosity of this type of gum. The influence of ion types and ionic strength on the viscosity of gum solutions were also determined. The effect of ionic strength on the intrinsic viscosity of Combretum glutinosum gum was used to determine the salt tolerance value and the chain stiffness parameters of this type of gum. This study exhibited that the values of chain stiffness parameter (B), and salt tolerance (S) of deacetylated gum in the range of 0.0574 to 0.0700 , and 0.083 to $0.101 \mathrm{dl} \times \mathrm{M}^{1 / 2} / \mathrm{g}$ respectively.
\end{abstract}

Keywords: C. glutinosum, Gum Habeil, intrinsic viscosity, Salt tolerance, Stiffness parameters

\section{Introduction}

Gums obtained from several genus of Acacia trees are extensively used in food industrial as emulsifiers, a thickeners, and adhesive agents. Combretum glutinosum gum in Sudan known as Gum Habeil, and this tree belongs to the Combretaceae family (Arbonnier, M., 2004, Devineau, J. L., 1999). The leaves of Combretum glutinosum trees have been used traditionally in Sudan for many years in the treatment of malaria, headache, bleeding, and utilized as diuretic (Jefferies, M., et al, 1981). Pousset 1993 publicized that, the hot aqueous extracted solution of Combretum glutinosum leaves has been used to therapy Hepatitis B virus (Jefferies, M., et al, 1978). The present work is an attempt to, determine the solubility of Combretum glutinosum gum in different solvents, measure the intrinsic viscosity and investigate the influence of ion types and ionic strength on the value of intrinsic viscosity of Combretum glutinosum gum. The work also aimed to determine the value of chain stiffness (B), and salt tolerance (S) parameters of deacetylated Combretum glutinosum gum. The author 2013 revealed that; the weight average molecular weight of AGP component of gum equal $8.611 \times 10^{5}, 4.456 \times 10^{6}$, and $1.528 \times 10^{6} \mathrm{~g} / \mathrm{mol}$., and radius of gyration $(\mathrm{Rg})$ equal $72.16,30.03$, and $81.3 \mathrm{~nm}$ of the freeze dried deacetylated gum, freeze dried soluble part, and freeze dried calcium- free gum respectively. Freeze dried soluble part gum shown a highly branched compact chain backbone (low radius of gyration) with higher weight average molecular weight than the modified gum samples "deacetylated and Calcium-free gums" (Awad, M.H., et al, 2013). The author 2013 revealed that; the thermal analysis of gum samples exhibited endothermic peak ranged from 30 to $45^{\circ} \mathrm{C}$ combined with heat content value ranged from 0.3 to $1.5 \mathrm{~J} / \mathrm{g}$ (Awad, M.H., et al, 2014).

\section{Sample Collection and Preparation}

Authenticated specimens of Combretum glutinosum gum collected from Blue Nile state - Sudan in seasons 2007 to 2009. The samples were cleaned from debris like sand and bark, then converted to Mechanical powder using an electrical grinder, and sieved using mesh size $250 \mu \mathrm{m}$.

\subsection{Solubility Measurement}

$1 \% \mathrm{w} / \mathrm{w}$ of gum in electrolyte (water) solution was stirred overnight. The dispersion solution was centrifuged at $3000 \mathrm{rpm}$ for $45 \mathrm{~min}$, then the soluble fraction was decanted and saved in $250 \mathrm{~cm}^{3}$ volumetric flask. Insoluble fraction was dissolved in $20 \mathrm{~cm}^{3}$ distilled water, then the mixture was stirred for $60 \mathrm{~min}$ and re-centrifuged at $3000 \mathrm{rpm}$ for $10 \mathrm{~min}$ before the supernatant fraction transferred to the soluble part solution using a dropper. The last steps were repeated three times to remove electrolyte salts. Insoluble fraction was stored for $24 \mathrm{hrs}$. in oven 
at $105{ }^{\circ} \mathrm{C}$ and then weighed, while the assembled soluble part solution was completed to $250 \mathrm{~cm}^{3}$ by adding distilled water, then $20 \mathrm{~cm}^{3}$ of soluble part solution was dried for $24 \mathrm{hrs}$. in oven at $105{ }^{\circ} \mathrm{C}$ and weighed (Jefferies, M., et al., 1981; Jefferies, M., et al., 1978).

\subsection{Determination of Gel Volume}

$50 \mathrm{~cm}^{3}$ of $2 \% \mathrm{w} / \mathrm{v}$ of gum in electrolyte solution was stirred overnight. The dispersion solution was centrifuged at $3000 \mathrm{rpm}$ for $45 \mathrm{~min}$, then the supernatant was decanted. $50 \mathrm{~cm}^{3}$ of electrolyte solution was added to the insoluble fraction, then the solution was stirred for $60 \mathrm{~min}$ and re-centrifuged at $3000 \mathrm{rpm}$ for $10 \mathrm{~min}$ and the supernatant was decanted. The last step was repeated three times before the final centrifugation. Lastly $50 \mathrm{~cm}^{3}$ of electrolyte solution was added to the gel fraction and the mixture was stirred for $10 \mathrm{~min}$, and allowed to stand for $20 \mathrm{hrs}$., then the gel volume was measured. The above experiment was carried using 0 to 0.3 ionic strength solutions of magnesium chloride, and calcium chloride, and sodium chloride (Brito, A. C. F., et al., 2004).

\subsection{Preparation of Deacetylated, and Soluble Part Gum Solutions}

Standard methods were used to prepare soluble part, and deacetylated gum solutions (Le Cerf, D., et al., 1990, Lapasin, R., \& Pricl, S., 1995).

\subsection{Intrinsic Viscosity Measurement}

$0.875 \mathrm{~g} / \mathrm{dl}$ of deacetylated gum, and soluble part solutions in different ionic strengths were prepared. Ubbelohde viscometer (75 / N94 or 75/ N 104) immersed in a viscometer bath (C.T-500 Series II, USA) was used to determine the flow time of the gum solutions flowing through the Ubbelohde capillary tube. The relative viscosity was measured by comparing the flow time of $3 \mathrm{~cm}^{3}$ of gum solution to the flow time of solvent passage through the Ubbelohde capillary tube, then the relative viscosity was converted to inherent, specific, and reduced viscosity (Le Cerf, D., et al., 1990).

\subsection{Salt Tolerance and Chain Stiffness Parameter}

The value of salt tolerance (S) was obtained from the following equation (Smidsrod, O., et al., 1971):

$$
[\eta]=[\eta] \infty+S \times 1 / \sqrt{ } \mu
$$

where $[\eta] \infty$ is the intrinsic viscosity at infinite ionic strength $(\mu)$. The relative stiffness parameter (B) was determined from the below equation:

$$
\mathrm{S}=\mathrm{B} \times([\eta] \mu=0.1) v
$$

where the $v$ constant used for this study equal 1.3 (Lapasin, R., et al., 1995).

\section{Results and Discussion}

\subsection{Solubility and Gel Volume}

Table 1 shows the solubility of Gum Habeil increased with the solvent basicity directly, the high solubility of gum solution in sodium carbonate due to calcium ion depletion. The weight of gel was calculated by discounting the weight of insoluble materials (sand and bark) from the total weight of the insoluble fraction. 
Table 1. Solubility of Gum Habeil in several solvents

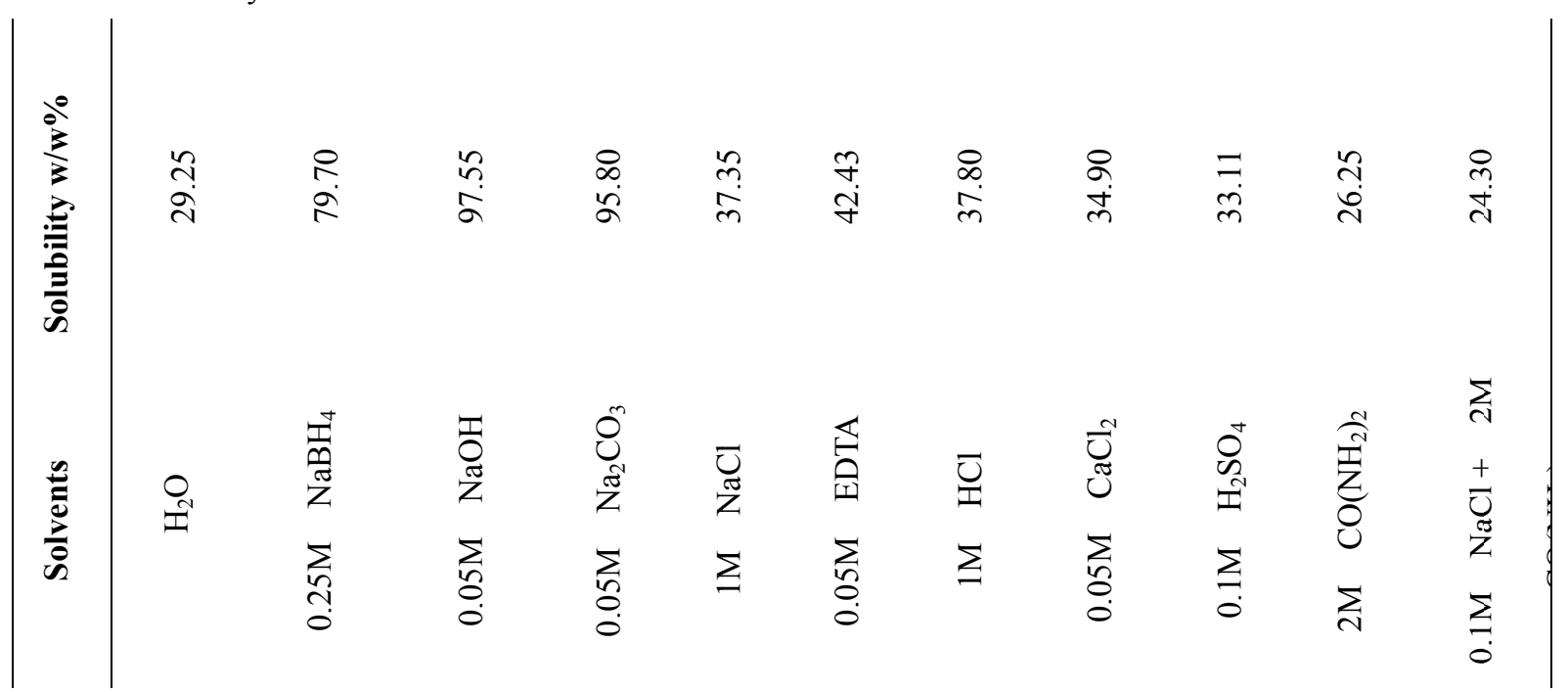

Fig.1 shows that solubility of Gum Habeil was effected by ionic strength of the dispersing medium.

When the ionic strength of sodium chloride increased from 0.001 to 0.9 at $\mathrm{pH}$ equal 7 progressively the gum solubility was increased from 30.5 to $37.5 \% \mathrm{w} / \mathrm{w}$ and this could be attributed to the greater activity and binding capacity of the chloride ions to the positively charged protein and polysaccharides groups, thereby enhancing its solubility. Fig. 1 also showed that at high ionic strength up to 0.9 the solubility of Gum Habeil was decreased steeply with the ionic strength increases, the relationship between the solubility of Gum Habeil and alkali salts ionic strength obeyed Cohn equation (Cohn, E. J.,1925).

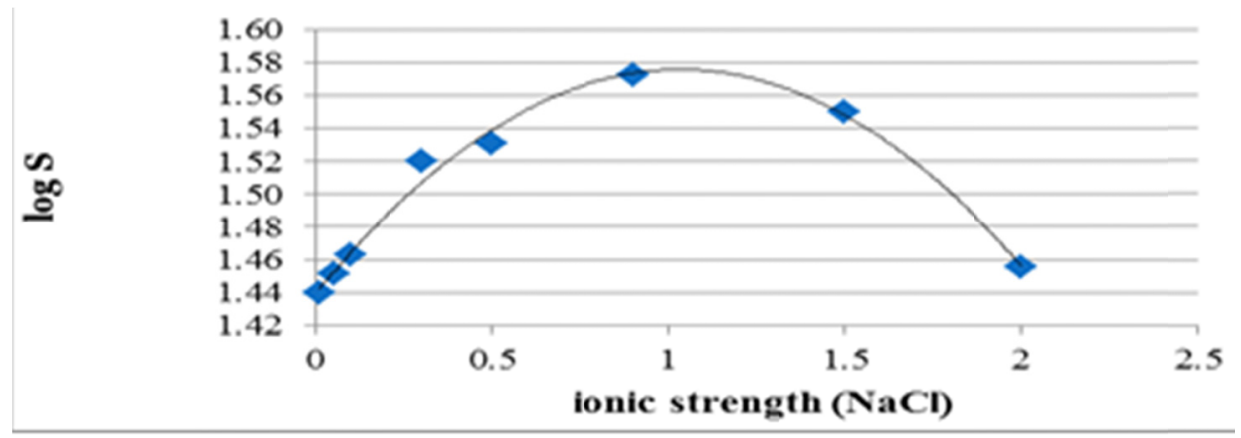

Figure 1. Ionic strength of sodium chloride versus $\log$ (solubility) of the Gum Habeil

Fig.2 illustrated the influencing of concentration of sodium carbonate, and $\mathrm{pH}$ on solubility of Gum Habeil. As the graph indicated, Gum Habeil solubility was $\mathrm{pH}$-dependent (the researcher attributed this for H-bonding broken in alkali medium and sugar hydrolysis), and a higher solubility increases observed at $\mathrm{pH}$ above 10 (Solubility $>95 \%$ ), also the solubility was steeply increased with removing of calcium ions that means $\mathrm{H}$ bonding and Calcium ions responsible for the hydrogel form. The behavior of Gum Habeil differs from Gum Gatti and similar to Khaya grandifoliolia (Aslam, M., et al., 1978, Greenwood, C. T., \& Matheson, N. K., 1956).

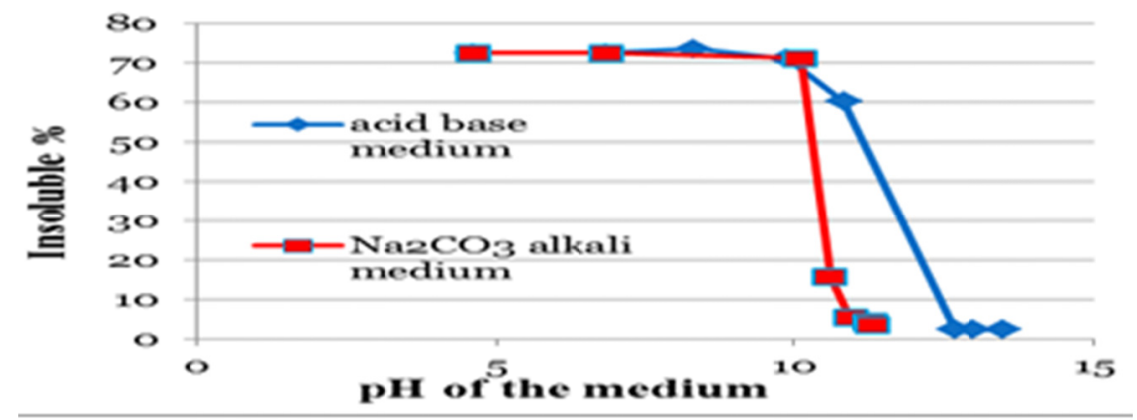

Figure 2. Effect of $\mathrm{pH}$ on the solubility of Gum Habeil solution 
Fig.3 showed that at the same ionic strength, the divalent ions $\left(\mathrm{Mg}^{+2}\right.$ and $\left.\mathrm{Ca}^{+2}\right)$ have a greater effect than monovalent ions $\left(\mathrm{Na}^{+}\right)$on decreasing the gel volume of Gum Habeil. Also Fig.3 shows the same Valente ions $\left(\mathrm{Mg}^{+2}\right.$ and $\left.\mathrm{Ca}^{+2}\right)$ at the same ionic strength, the small and light ions $\left(\mathrm{Mg}^{+2}\right)$ have a greater effect than the big and heavy ions $\left(\mathrm{Ca}^{+2}\right)$ on decreasing the gel volume of Gum Habeil. For all cations, at ionic strength more than 0.2 the gel volume is in depending on the charge of cations.

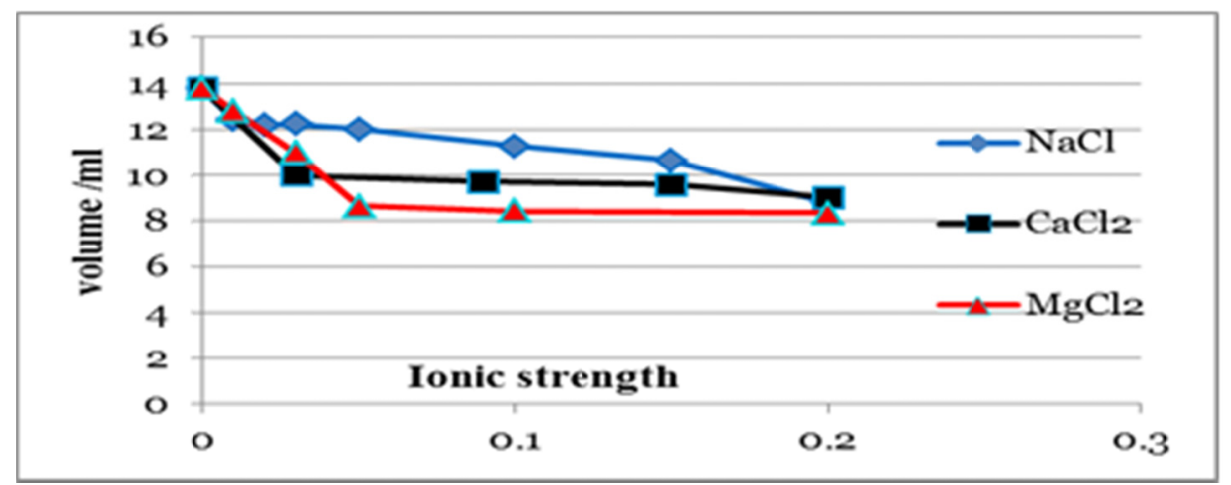

Figure 3. The effect of salt ionic strength on gel volume $\left(\mathrm{cm}^{3}\right)$ of Gum Habeil

\subsection{Estimation of Intrinsic Viscosity}

Fig.4 Showed that without salt addition, the reduced viscosity of Combretum glutinosum gum was increased steadily with dilution (from 0.5 to $0.2 \% \mathrm{w} / \mathrm{v}$ ), and a clear increase was observed for gum concentrations less than $0.235 \mathrm{~g} / \mathrm{dl}$. The ionic polysaccharides solutions have the same behavior, Pricl and Lapasin 1995 reported that, the neutral polysaccharide such as Acacia Senegal and locust bean gums observed linear relationships between experimentally reduced viscosity data and concentration of gum solution, while the ionic polysaccharides such as xanthan gum given a noticeable increases reduced viscosity value with decreases the concentration of gum solutions, and this attributed to the charge-charge electrostatic repulsion between ionic groups on polymer backbone and extended coil dimensions (Lapasin, R., \& Pricl, S., 1995), for this reason the experimentally data of reduced and inherent viscosity did not obey the Huggins and Kraemer equations.
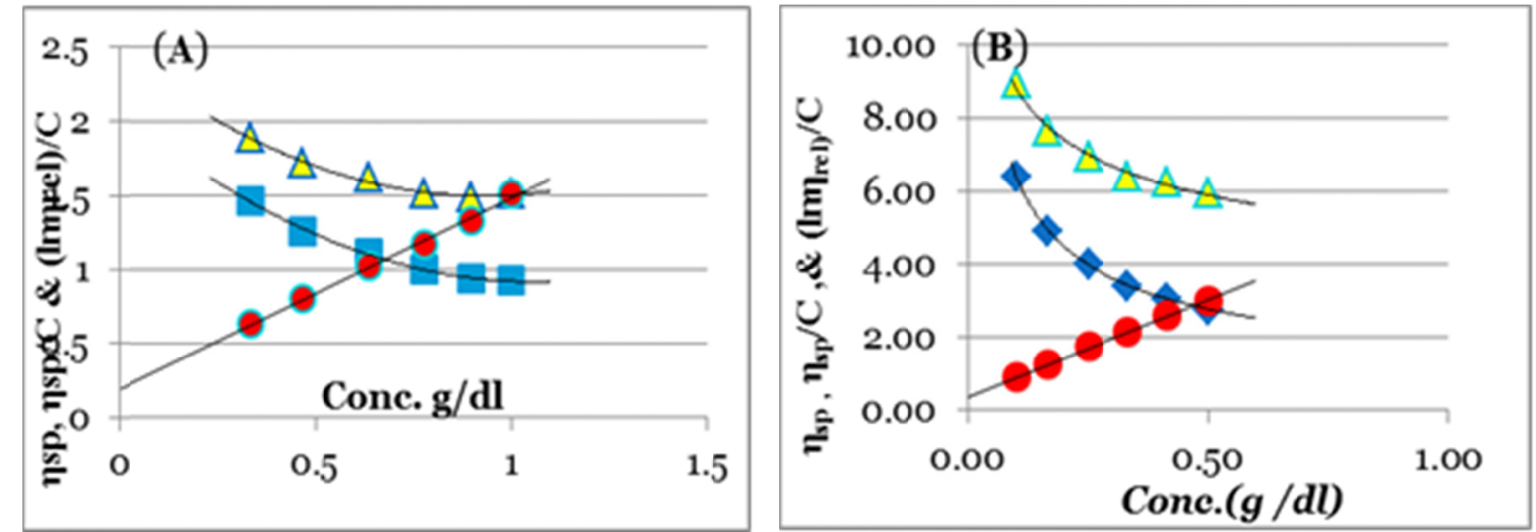

Figure 4. $\eta \mathrm{sp} \bigcirc, \eta_{\mathrm{sp}} / \mathrm{C} \boldsymbol{\Delta}$, and $\left(\ln \eta_{\mathrm{rel}}\right) / \mathrm{C} \vee$ versus concentration plots for $(\mathrm{A})$ water soluble part, (B) deacetylated gum in de- ionized water at $25 \pm 1^{\circ} \mathrm{C}$

The aim of this part of work is to apply some intrinsic extrapolated equations such as, Fouss, Schulz-Blaschke, Martin, Heller, and Fedors equations to linearize the viscometric data obtained in this study (Fedors, R. F., 1979). According to the data analysis; Fedors equation given the best linearize viscometric data with the lower standard deviation errors, this appeared that Fedors equation the best equation to calculating the value of intrinsic viscosity of Gum Habeil in aqueous solution. Table 2 shows the value of intrinsic viscosity of freeze dried soluble part gum calculated by the different extrapolated equations is lower than the value of freeze dried deacetylated gum, and this emphasized that the freeze dried soluble part gum have the compacted structure with smaller size than freeze dried deacetylated gum.

Table 2. Shows the intrinsic viscosity of freeze dried, soluble part and deacetylated gum in water by different extrapolated equations 


\begin{tabular}{cccccc}
\hline Equation & Fouss & Schulz.-Blaschkl & Martin & Heller & Fedors \\
\hline Soluble part: & & & & & \\
A & 0.338 & -0.210 & -0.169 & 0.413 & -1.89 \\
{$[\eta] \mathrm{dl} / \mathrm{g}$} & 2.899 & 2.099 & 2.050 & 2.058 & 2.074 \\
$\mathrm{R}^{2}$ & 0.931 & 0.848 & 0.887 & 0.967 & 0.999 \\
$\mathrm{DA}:$ & & & & & -0.113 \\
$\mathrm{~A}$ & -0.246 & 0.158 & -0.129 & -0.355 & 2.439 \\
{$[\eta] \mathrm{dl} / \mathrm{g}$} & 3.115 & 2.418 & 2.370 & 2.439 & 0.998 \\
$\mathrm{R}^{2}$ & 0.956 & 0.885 & 0.907 & 0.981 & \\
\hline
\end{tabular}

Soluble part $=$ water soluble fraction; $\mathrm{DA}=$ Deacetylated gum fraction; $\mathrm{A}=$ extrapolated equation constant

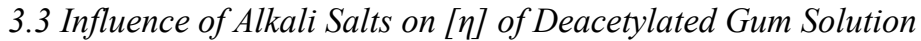

The hydrolysis of hydrophilic and hydrophobic functional groups performs a significant role on the polymer backbone conformation stability. The physicochemical study of the relation between solvent influence, and the hydrolysis properties of hydrophilic, and hydrophobic groups should provide insights into the role of solvent solute interactions associated with fundamental biopolymers phenomena (Wang, J. J., et al., 2000). The relation between relative viscosity of electrolytes solutions and solvent - solute interactions could be described by Jones and Dole equation below (Jones, G., \& Dole, M., 1925):

$$
\eta_{\mathrm{s}} / \eta_{\mathrm{o}}=\eta_{\mathrm{rel}}=1+\mathrm{A} \sqrt{ } \mathrm{C}+\mathrm{BC}
$$

where $\eta_{\mathrm{s}}$ is viscosity of gum solution, $\eta$ o represent viscosities of solvent, $A$ and $B$ are constants, and $C$ is the molar concentration of gum solution. A -Falkenhagen coefficient following the value of electrostatic forces related to ion-ion interactions, and B -coefficient exhibit the influence of solvent - solute interactions on the value of solution viscosity. Viscosity of neutral polysaccharides solution could be represented by the following equation:

$$
\eta_{\text {mix }} / \eta_{\mathrm{o}}=\eta_{\mathrm{rel}}=1+\mathrm{BC}
$$

where $\eta_{\text {mix }}$ represented viscosity of gum dissolved in mixture of two solvents with a fixed molar concentration, $\eta_{\mathrm{o}}$ is viscosities of mixture solvent.

Table 3. The values of A- Falkenhagen coefficient and B- coefficients of deacetylated gum in deionized water and different salts at $25^{\circ} \mathrm{C}$

\begin{tabular}{cccccccccccc}
\hline Salts & $\mathbf{H}_{\mathbf{2}} \mathbf{O}$ & \multicolumn{4}{c}{$\mathbf{K C l}$} & \multicolumn{3}{c}{$\mathbf{N a C l}$} & \multicolumn{3}{c}{$\mathbf{C a C l}_{\mathbf{2}}$} \\
\hline $\mathbf{m M}$ & 0.00 & 2.5 & 25 & 100 & 500 & 2.5 & 25 & 100 & 1000 & 2.5 & 25 \\
$\mathbf{A} / \mathbf{d l . g} \mathbf{g}^{\mathbf{2}}$ & 1.67 & -0.60 & -0.30 & -0.21 & -0.19 & -0.46 & -0.43 & -0.41 & -0.23 & -0.89 & -0.39 \\
$\mathbf{B} / \mathbf{d l .} \mathbf{g}^{-1}$ & 3.62 & 4.67 & 2.23 & 1.86 & 1.63 & 4.57 & 2.67 & 2.33 & 1.90 & 3.94 & 2.26 \\
$\mathbf{R}^{\mathbf{2}}$ & 0.99 & 0.99 & 0.992 & 0.97 & 0.99 & 0.99 & 0.995 & 0.997 & 0.994 & 0.990 & 0.98 \\
\hline
\end{tabular}

Table 3 showed that the B- coefficients value was decreased with the alkali salts concentration increased, in contrast A- Falkenhagen coefficient value was increased with the alkali salts concentration decreased. Also Table3 exhibited that the B- coefficients values of Gum Habeil in alkali salts concentration are positive and higher than A- coefficients, and this emphasizes that the increases of alkali salts concentration lead to decrease the B-coefficients values, increases the interaction between gum and alkali salt solvent, and this decreases the gum viscosity.

\subsection{Influence of Alkali Salts on Viscosity of Deacetylated Gum}

Fig. 5 to 7 showed that with alkali salts addition, the repulsion forces between the opposite functional group in chain segments was eliminated. Results exhibited that internet, and reduced viscosity versus gum concentration are given linear relationship in high concentration of alkali salt, and experimentally viscosity data obey Huggins and Kraemer equations with the lower standard deviation errors. Thus, this observation may be due to shielding the charge on the side chain of the polymer. 

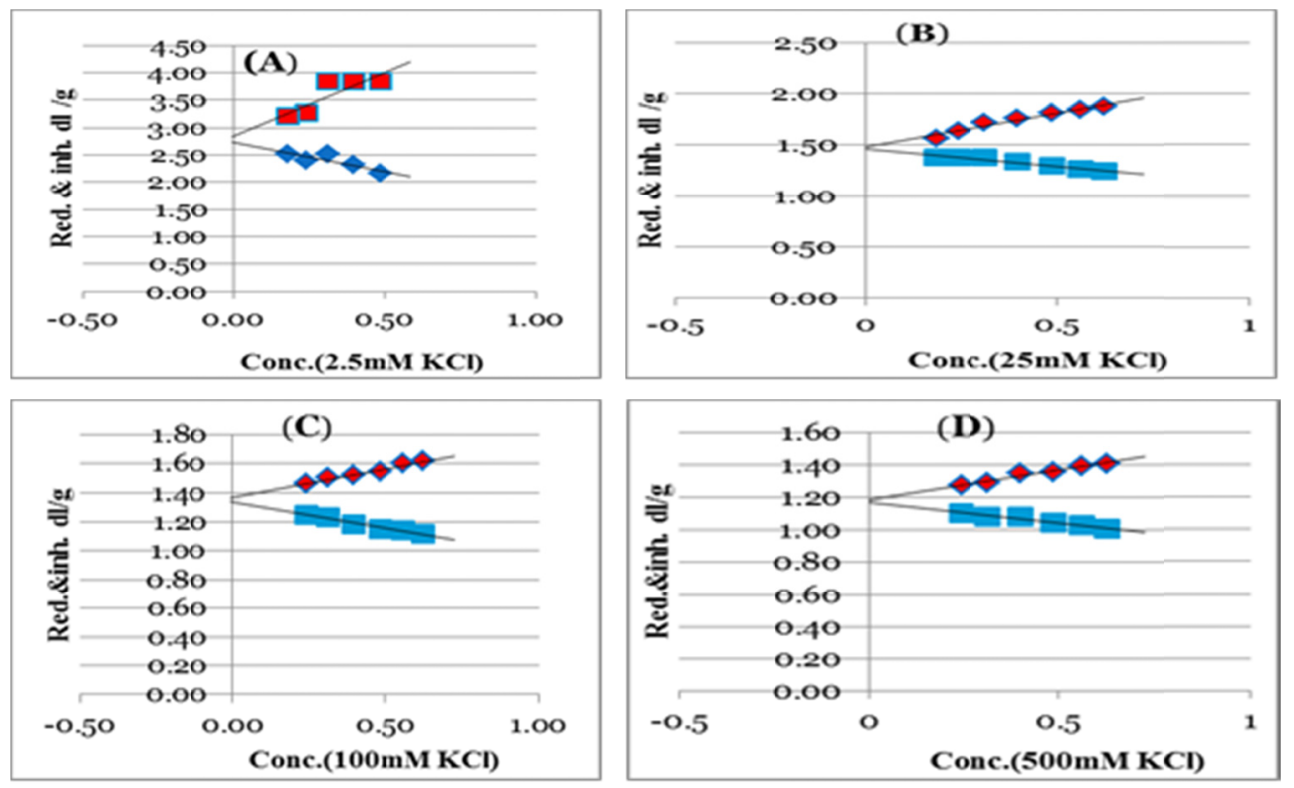

Figure 5. A, B, Cand D, represented $\downarrow \eta_{\mathrm{sp}} / \mathrm{C}$, and

$\eta_{\text {inh }}$ viscosity vs. gum concentration in different solvent concentrations, A 2.5, B 25, C 100, and D $500 \mathrm{mM}$ of $\mathrm{KCl}$
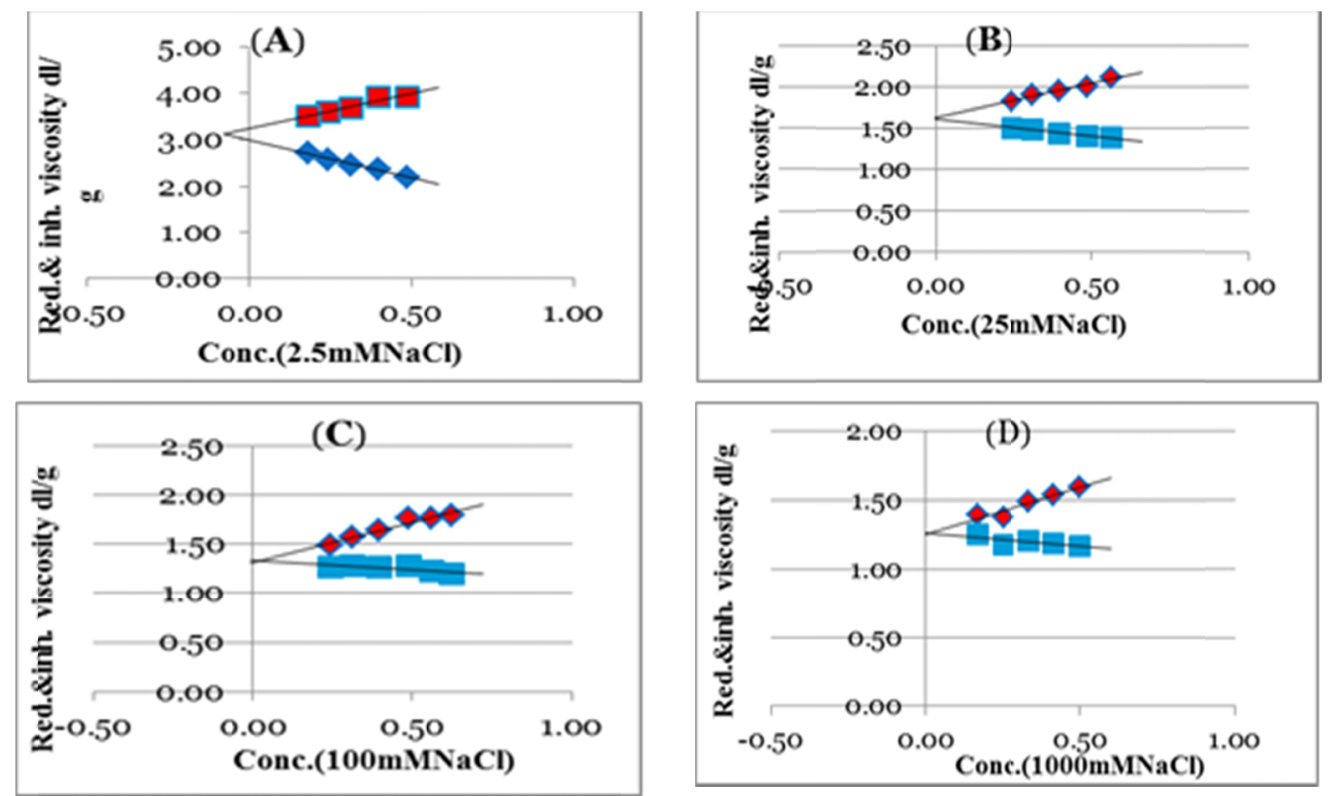

Figure 6. A, B, C and D, represented $\downarrow \eta_{\mathrm{sp}} / \mathrm{C}$, and $\square \eta_{\text {inh }}$ viscosity vs. gum concentration in different solvent concentrations, A 2.5, B 25, C 100, and D 500mM of NaCl
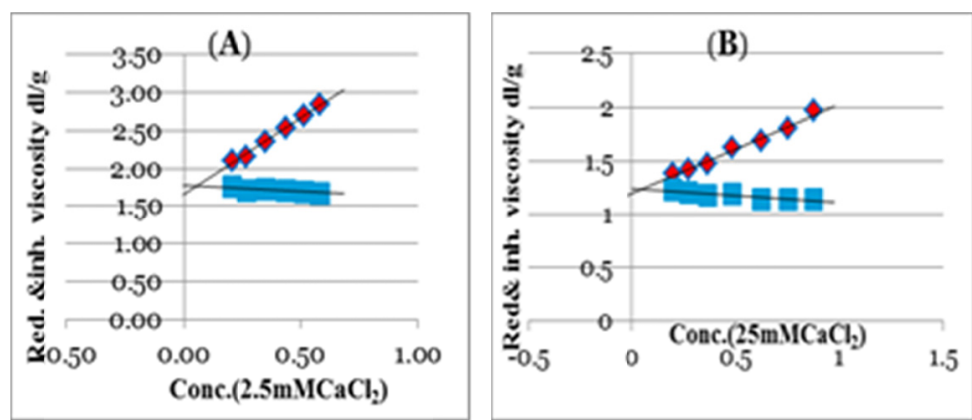

Figure 7. A, B, and C, represented $\bullet \eta_{\text {sp }} / \mathrm{C}$, and

$\eta_{\text {inh }}$ viscosity vs. gum concentration in different solvent 


\section{concentrations, A 2.5, B 25 , and C $500 \mathrm{mM}$ of $\mathrm{CaCl}_{2}$}

\subsection{Salt Tolerance and Chain Stiffness Parameters}

Fig.8 shows that the salt tolerance of deacetylated gum ranged from 0.083 to $0.101 \mathrm{dl} \times \mathrm{M}^{1 / 2} / \mathrm{g}$ with mean value of intrinsic viscosity at infinite ionic strength equal $1.0425 \mathrm{dl} / \mathrm{g}$. For electrolyte solution of polymer, the salt tolerance parameter is significantly depending on the nature of counter ions (cation) and polymer molecular mass, the salt tolerance (S) of some polysaccharides can be developed only when the comparison was expressed at a specific molecular mass. According to this fact, Smidsrod and Haug suggested a new parameter (B) is independent on the polysaccharide molecular mass, but the parameter (B) depends only on chain stiffness, for this reason the comparison with polyelectrolyte's of different chemical structures is possible, also the (B) parameter can be calculated without molecular weight determination (Smidsrod, O., \& Haug, A., 1971, Anthonsen, M.W., et al., 1993). The chain stiffness parameter (B) of deacetylated gum was ranged from 0.0574 to 0.0700 , which was similar to the some polysaccharides, such a carboxyl methyl cellulose, carrageen an and chitosan (Lapasin, R., \& Pricl, S., 1995).

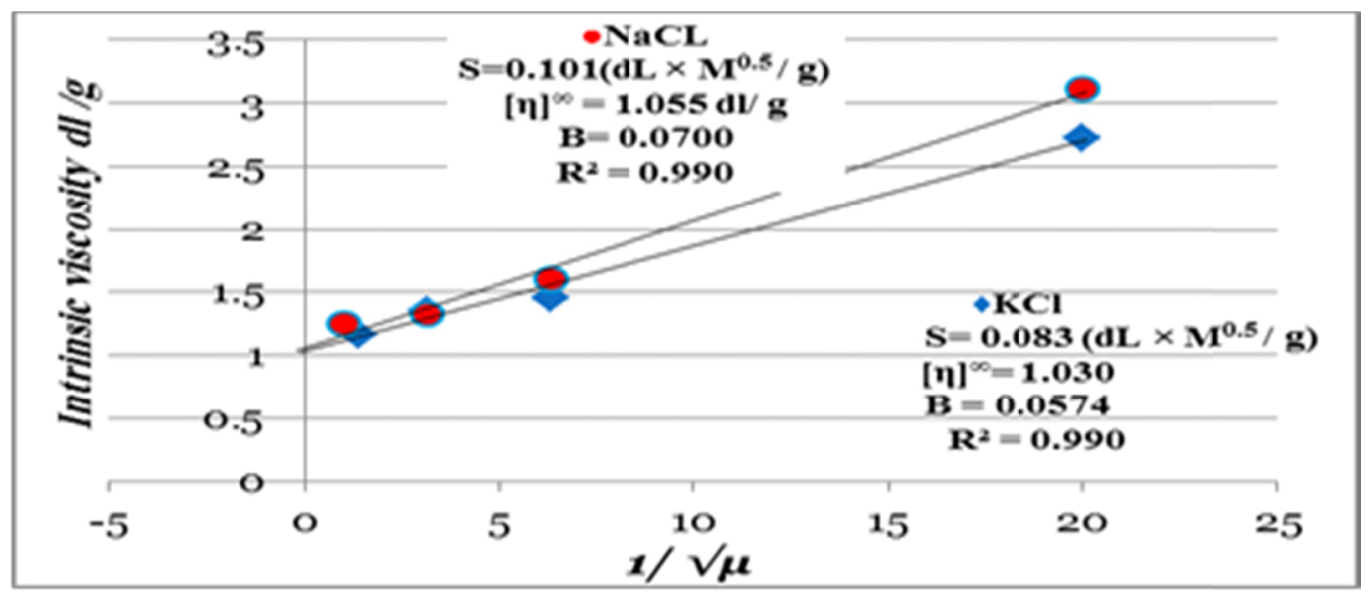

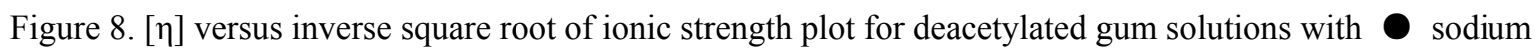
chloride, and potassium chloride addition

\section{Conclusion}

Combretum glutinosum gum was fractionated to a water soluble part 30 to $40 \% \mathrm{w} / \mathrm{w}$, and gel fraction 70 to $60 \%$ $\mathrm{w} / \mathrm{w}$. Although the percentage of calcium ion in gum samples equal $1.3 \% \mathrm{w} / \mathrm{w}$. This study revealed that the gel fraction have a higher ratio of calcium ion $62.23 \%$ of the total amount of calcium in gum samples, and this is the reason of gel formation, when solvents precipitate calcium ions this increases the gum solubility. In the absence of alkali salts, the viscosity experimental data of freeze dried soluble part and freeze dried deacetylated gum solutions over a wide concentration range was plotted in terms of Fouss, Schulz - Blaschke, Martin, Heller, and Fedors equations. All the equations linearized the viscosity experimental data and straight lines were attained, but Fedors equation showed the beast fitting of viscosity data with low value of standard deviation error. By Fedors equation, intrinsic viscosity of freeze dried soluble part, and freeze dried deacetylated gam in distilled water equal 2.0741 and $2.439 \mathrm{dl} / \mathrm{g}$ respectively. Results show that the salt tolerance parameter (S) of Habeil gum was found to be in the range of 0.083 to $0.101 \mathrm{dl} \times \mathrm{M}^{1 / 2} / \mathrm{g}$, and stiffness parameter (B) of gum was ranged from 0.0574 to 0.0700 .

\section{Acknowledgements}

The author thank the Ministry of higher education - Sudan, for the financial support. My thanks also are extended kindly to PHRC, UK. for allowing me to undertake a part of the practical work at Glyndwr University, Wrexham.

\section{References}

Anthonsen, M. W., Varum, K. M., \& Smidsrod, O. (1993). Solution properties of chitosans: conformation and chain stiffness of chitosans with different degree of N acetylation. Carbohydrate Polymers, 22, 193-201. http://dx.doi.org/10.1016/0144-8617(93)90140-Y

Arbonnier, M. (2004). Trees shrubs and lianas of West African dry zones. CIRAD, Montpellier; Museum national d'histoire naturelle, Paris, 56, 334-336. 
Aslam, M., P., \& Phillips, G. O. (1978). the effect of divalent metal on the viscosity of khaya gum. J. Chem. Res., 320- 321.

Awad, M. H., Elkhidr, H. E., Hassan, E. A., \& Osman, M. E. (2014). Morphological and physicochemical characterization of Combretum glutinosum Gum. Shendi University Journal, 14, 20-37.

Awad, M. H., Hassan, E. A., Osman, M. E., Saphwan, A., \& Phillips, G. O. (2013). Emulsification Properties and Molecular Weight Distribution of Combretum Glutinosum Gum. Jordan Journal of Chemistry, 8(3), 139-151. http://dx.doi.org/10.12816/0001524

Brito, A. C. F., Silva D. A., De Paula, R. C. M., \& Feitosa, J. P. A. ( 2004). Sterculia striata exudates polysaccharide: Characterization, rheological properties and comparison with Sterculia urens (karaya) polysaccharide. Polymer International, 53, 1025-1032. http://dx.doi.org/10.1002/pi.1468

Cohn, E. J. (1925). The physical chemistry of proteins, Physiol Rev 5349- 437.

Devineau, J. L. (1999). Journal of Tropical Ecology, 15, 497-513. http://dx.doi.org/10.1017/S0266467499000978

Fedors, R. F. ( 1979). Polymer, 20, 225. http://dx.doi.org/10.1016/0032-3861(79)90226-X

Greenwood, C. T., \& Matheson, N. K. ( 1956). the interaction between complex acid polysaccharides in solution and metal ions. Chem. Ind., 75,988.

Jones, G., \& Dole, M. (1929). J. Am. Chem. Soc., 51, 2950-2964. http://dx.doi.org/10.1021/ja01385a012

Jefferies, M. P., \& Phillipdsm O. G. (1981). Cations effects on the viscosity of Gum Gatti. J. Sci., Food Agric.

Jefferies, M. P., \& Phillipds, O. G. ( 1978). The viscosity of aqueous solutions of Gum Gatti. J. Sci., Food Agric., 29, 193-200.

Lapasin, R., \& Pricl, S. (1995). Rheology of polysaccharide systems. Rheology of industrial polysaccharides: theory and applications, 250-494.

Le Cerf, D., Irinei, F., \& Muller, G.(1990). Solution properties of gum exudates from Sterculia urens (karaya). Carbohydrate Polymers, 13, 375-386. http://dx.doi.org/10.1016/0144-8617(90)90037-S

Smidsrod, O., \& Christensen, B. E., Guiry, I. M. D., \& Blunden, G. ( 1991). Seaweed resources in Europe: uses and potential, Chichester: Wiley, 185-217.

Smidsrod, O., \& Haug, A. (1971).Estimation of the relative stiffness of molecular chain in polyelectrolytes from measurement of viscosity at different ionic strengths. Biopolymers, 10, 1213-1227. http://dx.doi.org/10.1002/bip.360100711

Wang, J. J., Yan, Z. N., Zhang, H. C., \& Lu, J. S. (2000). Biophys. Chem., 86, 71-78. http://dx.doi.org/10.1016/S0301-4622(00)00160-5

\section{Copyrights}

Copyright for this article is retained by the author(s), with first publication rights granted to the journal.

This is an open-access article distributed under the terms and conditions of the Creative Commons Attribution license (http://creativecommons.org/licenses/by/3.0/). 